\title{
COVID 19 and Pancytopenia: A Single Case Experience of a Pediatrics Institute
}

\author{
Neema Tiwari ${ }^{1}$, Nita Radha Krishnan ${ }^{2}$, Savitri Singh ${ }^{1}$, Jyotsna Madan ${ }^{1}$, Devajit Nath $^{1}$, Sangeeta Tripathi ${ }^{3}$, Ravi
} Shankar ${ }^{2 *}$, Umesh Shukla ${ }^{4}$

${ }^{1}$ Department of Pathology, ${ }^{2}$ Department of Pediatric Hemato-oncology, ${ }^{3}$ Department of Radiology, ${ }^{4}$ Department of Gastroenterology, Super Specialty Pediatric Hospital and Post Graduate Teaching Institute, NOIDA

${ }^{4}$ Associate Professor, Department of Radiology, Super Specialty Pediatric Hospital and Post Graduate Teaching Institute, NOIDA

DOI: $\underline{10.36348 / \text { sjpm.2020.v05i05.016 }}$

| Received: 02.05.2020 | Accepted: 22.05.2020 | Published: 30.05 .2020

*Corresponding author: Dr. Savitri Singh

\section{Abstract}

Introduction: The COVID-19 pandemic has paralyzed the world machinery and the whole world has been battling this crisis with large number of deaths. India reported its first case in January 2020 in Kerala [1]. Experimental research findings indicate that an exaggerated immune response and a strong cytokine storm, which may include high levels of granulocyte-macrophage colony-stimulating factor and interleukin-6 (IL-6), are activated in severe COVID-19 [3, 4]. This can lead to a clinical presentation of pancytopenia and HLH like features. Case: A 15-year-old female presented with fever and breathing difficulties to the department of pediatric hemato-oncology. She had tachypnoea and tachycardia but no organomegaly, lymphadenopathy or any other relevant examination findings. Routine lab investigations revealed pancytopenia. Day 1 peripheral smear showed virocytes. Her chest X ray showed a patch. She was evaluated for COVID19 and came out to be positive. On treatment her symptoms subsided but pancytopenia persisted. Hence a repeat peripheral smear examination and done on day 10 post admission which showed $8 \%$ blasts. A bone marrow examination was done and flowcytometry sent which revealed Acute Lymphoblastic Leukemia Result: A diagnosis of acute leukemia was made on imprint smears as bone marrow aspiration was hemodiluted and paucicellular. Biopsy showed presence of sheets of histiocytes with hemophagocytosis admixed with blasts. A final diagnosis of Acute leukemia with Hemophagocytosis was made and serum ferritin advised to rule out HLH. Conclusion: The case turned out to an ALL with HLH. Hence, we realized that the cytokine storm in COVID -19 can at times mask the underlying major etiology and patient might just present with HLH. We conclude it is very important to analyze each case of Covid with great alacrity

Keywords: HLH, hemophagocytosis, COVID-19, Pancytopenia, Acute leukemia, cytokine storm.

Copyright @ 2020: This is an open-access article distributed under the terms of the Creative Commons Attribution license which permits unrestricted use, distribution, and reproduction in any medium for non-commercial use (NonCommercial, or CC-BY-NC) provided the original author and sources are credited.

\section{INTRODUCTION}

India reported its first case in January 2020 in Kerala and Delhi and NCR reported its case in March 2020 [1]. The main presentation of this disease till now has been pneumonia leading to ARDS and patient death. However slowly multisystem involvement by COVID leading to gastrointestinal involvement causing diarrhea, hypercoagulable state leading to DIC /CAC and pulmonary embolism, CNS involvement etc. is being seen increasingly. In pediatric population Kawasaki like features and skin changes are also being rapidly recognized [2].

One important thing that has come to the forefront in COVID infection pathogenesis is that it manifests with severe symptoms in individuals with lower immunity or co morbidities like diabetes, hypertension, post chemotherapy, long standing chronic diseases etc. Experimental research findings indicate that an exaggerated immune response and a strong cytokine storm, which may include high levels of granulocyte-macrophage colony-stimulating factor and interleukin-6 (IL-6), are activated in severe COVID-19 $[3,4]$.

Here we present a case of a 15-year-old female who presented with fever, breathing difficulties to the emergency and was later on diagnosed as a case of Acute leukemia with Covid 19 infection with Hemophagocytic Lymphohistiocytosis (HLH). 


\section{CASE REPORT}

A 15-year-old female presented with fever and breathing difficulties to the emergency. She had tachypnoea and tachycardia but no organomegaly, lymphadenopathy or any other relevant examination findings. Routine lab investigations revealed pancytopenia, hemoglobin levels were $8.68 \mathrm{gm} / \mathrm{dl}$ and RBC were 2.85 million $/ \mathrm{mm}^{3}$. Her TLC $-2.5 \times 10^{3} / \mathrm{mm}^{3}$, ANC- $1.77 \times 10^{3} / \mathrm{mm}^{3}$, absolute lymphocyte count was reduced $-0.62 \times 10^{3} / \mathrm{mm}^{3}$, monocyte and eosinophil within normal limits and platelet count $84.9 \times 10^{3} / \mathrm{mm}^{3}$.

Peripheral smear on the day of admission (day 1) showed normocytic normochromic to few fragmented RBCs and few macrocytic cells. WBC showed few mid-series myeloid cells with toxic granules, few atypical lymphoid cells and few large granular lymphocytes resembling virocytes. Platelet count was reduced. No blasts were seen. In suspicion, she underwent testing for COVID and came out to be positive. She was started treatment for the same and although she responded clinically her pancytopenia persisted.
A repeat peripheral smear examination 10 days post her admission (day 11), to assess the reason for persistent pancytopenia was done which revealed, $8 \%$ blasts in the smear, having high $\mathrm{N}: \mathrm{C}$, opened up chromatin, few with hand mirror morphology. Bone marrow aspirate smears were hemodiluted with very less cellularity, however cellular imprint smears showed presence of blasts. Admixed with the blasts were few macrophages with hemosiderin pigment and phagocytosed cells (polymorph). A diagnosis of acute leukemia was made and flowcytometry advised. On examining the biopsy, a tightly packed cellular marrow showed presence of blasts in clusters admixed with clusters of macrophages fair number showing hemphagocytosed erythroid precursors as well as debris. Few pockets of preserved hematopoietic cells with megakaryocytes and erythroid precursors and few myeloid precursors also seen. Focal serous degeneration and fibrosis also seen. Hence a diagnosis of Acute leukemia with co-existing hemophagocytosis was made. Serum ferritin levels were advised with flowcytometry and immunohistochemistry. A final diagnosis of Acute lymphoblastic lymphoma was made. The patient is now negative for corona virus and on chemotherapy and she is stable.

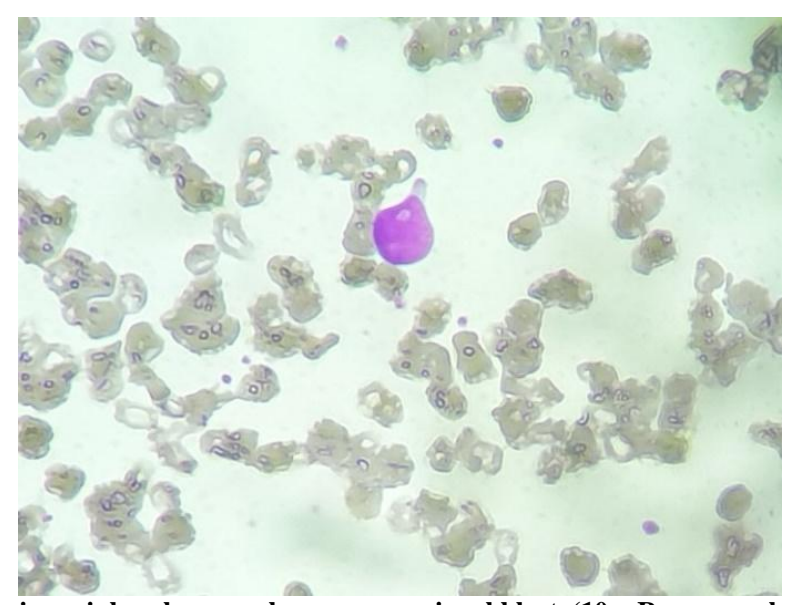

Fig-1: Pancytopenic peripheral smear shows an occasional blast. (10x, Romanowsky stain-Leishman)

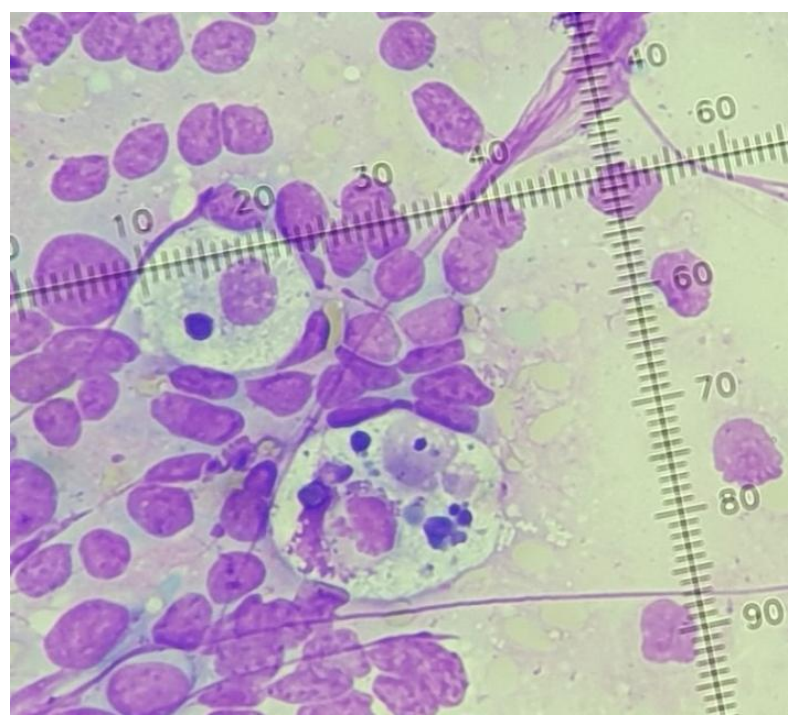

Fig-2: Hemophagocytosis(polymorph,hemosiderin) in imprint smear with blasts 


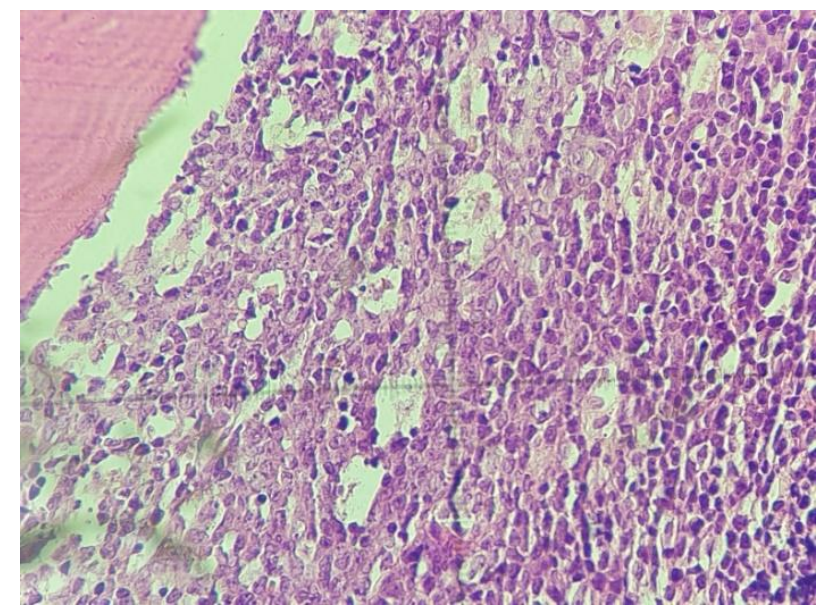

Fig-3: Scattered macrophages in between blasts few with hemophagocytosis

\section{DISCUSSION}

Corona virus disease 2019 (COVID-19) is an infectious viral disease caused by a pathogen named severe acute respiratory syndrome coronavirus 2 (SARS-CoV-2) [3]. COVID-19 has created a public health emergency in many countries, including India, and is expected to continue to spread. Corona virus are known to cause flu-like upper respiratory illnesses in humans, but the current strain, SARS-CoV-2, was not known to cause any human illnesses prior to this outbreak. Thus, very little information about COVID19 's pathogenic role in humans is known.

Most of the patient morbidity and mortality attributable to COVID-19 has been reported in Wuhan, China $[5,6]$. Following the recent availability of COVID-19 testing, it is likely the number of diagnosed cases will significantly increase. It is common knowledge that cytokine storm (IL1, IL-6) is more prevalent in immunocompromised patients leading to disease severity. Manifestation of HLH could also be a part of this mechanism [7, 8].

In this short case report, we wanted to highlight that diagnosis of corona virus with co-existing pancytopenia could have been only attributed to viral induced HLH and no bone marrow performed hence missing the leukemia. Even we thought of leukemia only after examining the second peripheral smear after 10 days of admission as the first smear showed only virocytes. This finding is unique and puts forth the question that was the degree of viral onslaught stronger than the presence of underlying leukemia that all the cells in peripheral smear were masquerading virocytes rather than blasts? Could this morphological change be brought about by the said cytokine storm?
Hence, we conclude it is very important to analyze each case of Covid with great alacrity, as they are many unanswered questions still about the presentation and pathogenesis of this virus.

\section{REFERENCES}

1. Indian council of medical research India Covid 19 updates. https://main.icmr.nic.in/content/covid-19

2. Zhang, X., Song, K., Tong, F., Fei, M., Guo, H., Lu, Z., ... \& Zheng, C. (2020). First case of COVID-19 in a patient with multiple myeloma successfully treated with tocilizumab. Blood advances, 4(7), 1307-1310.

3. Anand, A., Gray, E. S., Brown, T., Clewley, J. P., \& Cohen, B. J. (1987). Human parvovirus infection in pregnancy and hydrops fetalis. New England Journal of Medicine, 316(4), 183-186.

4. Özdemir, N., Akı, H., Hakyemez, H. T., Çokuğraş, F. Ç., \& Apak, H. (2010). Parvovirus B19 infection mimicking juvenile myelomonocytic leukemia. International Journal of Infectious Diseases, 14, e379-e380.

5. Mitra, A., Dwyre, D. M., Schivo, M., Thompson III, G. R., Cohen, S. H., Ku, N., \& Graff, J. P. (2020). Leukoerythroblastic reaction in a patient with COVID- 19 infection. American Journal of Hematology.

6. Gostin, L. O., \& Lucey, D. (2015). Middle East respiratory syndrome: a global health challenge. Jama, 314(8), 771-772.

7. https://www.cdc.gov/coronavirus/types.html

8. Wu, Z., \& McGoogan, J. M. (2020). Characteristics of and important lessons from the coronavirus disease 2019 (COVID-19) outbreak in China: summary of a report of 72314 cases from the Chinese Center for Disease Control and Prevention. Jama, 323(13), 1239-1242. 